\title{
Development and Validation of RP-HPLC Method for Simultaneous Estimation of Levocloperastine Fendizoate and Chlorpheniramine Maleate in their Combined Dosage Form
}

\author{
Sharma $\mathrm{B}^{1}$, Satone $\mathrm{D}^{2}$, Pradhan $\mathrm{P}^{1}$, J ain $\mathbf{H}^{\mathbf{1}}$ and \\ Meshram D ${ }^{1 *}$ \\ ${ }^{1}$ Department of Quality Assurance, Pioneer Pharmacy \\ Degree College, India \\ ${ }^{2}$ University Department of Pharmaceutical Sciences, RTM \\ Nagpur University, India \\ *Corresponding author: Dhananjay Meshram, \\ Department of Quality Assurance, Pioneer Pharmacy \\ Degree College, India
}

Received: March 20, 2017; Accepted: April 12, 2017; Published: April 19, 2017

\begin{abstract}
A simple and rapid RP-HPLC method has been developed and validated for the simultaneous determination of Levocloperastine fendizoate and Chlorpheniramine maleate syrup formulation. Resolution of the analytes was achieved within $10 \mathrm{~min}$, employing a mixture of $10 \mathrm{mM}$ mobile phase Buffer $(\mathrm{pH}$ 6.5): Acetonitrile $(50: 50, \% \mathrm{v} / \mathrm{v})$ as isocratic mobile phase, pumped at $1.0 \mathrm{~mL} /$ min through a C18 column ( $5 \mu \mathrm{m}$ particle size). The detection wavelength for the analytes was $227 \mathrm{~nm}$. The system suitability parameters were found to be acceptable. The linearity of response $\left(r^{2}>0.999\right)$ in the appropriate ranges (from $50 \%$ up to $150 \%$ of the expected concentrations of the analytes in the formulations), method accuracy (RSD $<2.0 \%$ ), repeatability and intermediate precision $(\mathrm{RSD}<2.0 \%)$, were confirmed. Robustness result indicates that the methods performance can withstand small variations in method parameters. Satisfactory results obtained in terms of analyte recovery and RSD, while analyzing marketed pharmaceutical preparations. Hence the method can be useful for regular analysis of this combination in marketed syrup formulation.
\end{abstract} HPLC

Keywords: Levocloperastine fendizoate; Chlorpheniramine maleate; RP.

\section{Introduction}

Chlorpheniramine maleate (CPM), 3-(p-chlorophenyl)3-(2-pyridyl)-N,N-dimethyl propylamine (Figure 1) [1] is a firstgeneration alkyl amine antihistamine, act by antagonizing $\mathrm{H1}$ receptors. It is commonly used for symptomatic relief of the common cold and allergic rhinitis with mild sedative property [2].

Levocloperastine (LCF) i.e. 1-\{2-[(4-chloro-phenyl)phenylmethoxy]- ethyl\}-piperidine (Figure 2) [3], is a drug with a central antitussive effect and it is also endowed with an antihistaminic (sharing an ethylamine moiety with $\mathrm{H} 1$ receptor antagonists) and papaverine like activity similar to codeine, but without its narcotic effects. Pharmacological studies have revealed LCF acts on the cough center, without any depression of respiratory center in brain [4].

Literature survey revealed few quantitative techniques like RPHPLC [5-16], UV spectroscopy [17-19], TLC [20] methods for CPM and RP-HPLC method [21], UV spectroscopy [22] for LCF are available. So far to our present knowledge, no validated analytical high performance liquid chromatography (HPLC) method was available in literature for this combination in syrup formulation. Therefore, the purpose of this study was to develop and validate a HPLC methodology for the simultaneous determination of LCF and CPM in their combined syrup formulations, which has no literature precedents.

\section{Materials and Methods}

\section{Apparatus}

The chromatographic system utilised for development of method consists of a pump (Shimadzu LC 10AT VP) with a universal loop injector (Rheodyne 7725i) with a capacity of $20 \mu \mathrm{L}$, SPD 20A UV Detector and Hypersil BDS C18 $(25 \mathrm{~cm} \times 4.6 \mathrm{~mm}$ i.d. $\times 5 \mu \mathrm{m})$ column. The equipment was controlled by a PC work station equipped with CLASS M 10-VP software (Shimadzu, Kyoto, Japan). A UV/ Visible double beam spectrophotometer (Shimadzu Model 1800) was employed with a spectral bandwidth of $1 \mathrm{~nm}$ and a wavelength accuracy of $0.2 \mathrm{~nm}$ (with automatic wavelength correction using a pair of $1 \mathrm{~cm}$ matched quartz cells).

\section{Chemicals and solvents}

Chlorpheniramine maleate was procured from Oasis laboratory and Levocloperastine fendizoate was obtained as gift sample from LGM Pharma. HPLC grade methanol, acetonitrile and water bought from Merck India. Marketed formulation (Levotus syrup, Shasun Pharmaceuticals Pvt. Ltd, India) containing LCF 20mg and CPM $4 \mathrm{mg}$, bought from local pharmacy.

\section{Preparation of standard solutions}

Standard solutions of CPM $(40 \mu \mathrm{g} / \mathrm{mL})$, LCF $(200 \mu \mathrm{g} / \mathrm{mL})$ were prepared in $\mathrm{MeOH}$ and stored in volumetric flask and utilized as stock solution. Solution was found to be stable for 15 days. Working 


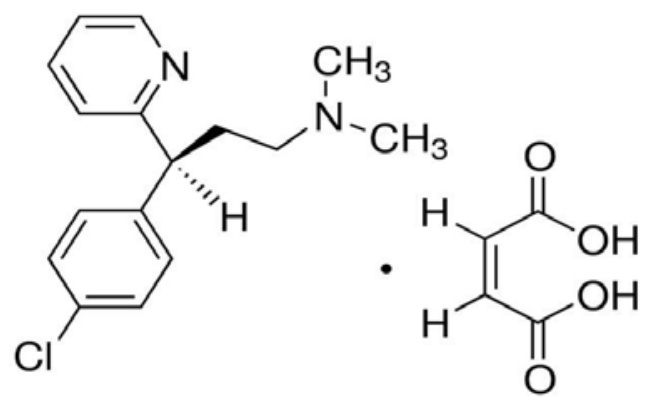

Figure 1: Chemical structure of Chlorpheniramine maleate.

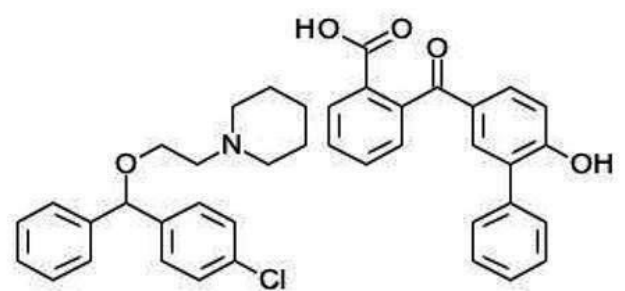

Figure 2: Structure of Levocloperastine fendizoate.

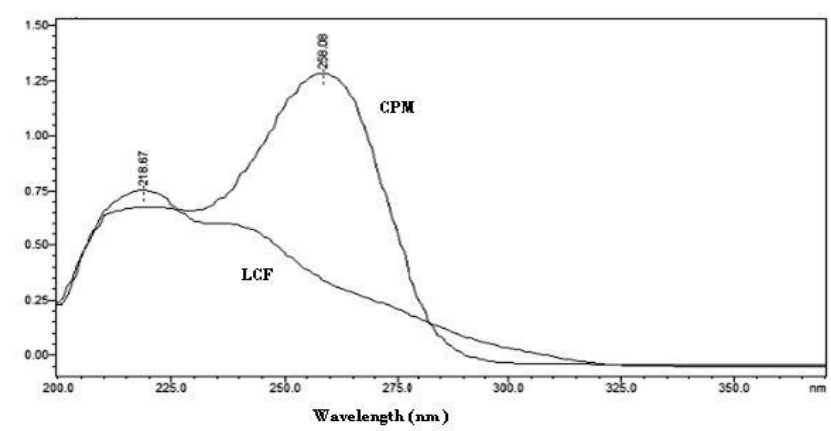

Figure 3: Absorption spectra of the analytes in the 200-400nm region. CPM $(4.0 \mu \mathrm{g} / \mathrm{mL}), \mathrm{LCF}(20.0 \mu \mathrm{g} / \mathrm{mL})$ in the optimized mobile phase.

standard solutions of CPM $(4 \mu \mathrm{g} / \mathrm{mL}), \mathrm{LCF}(20 \mu \mathrm{g} / \mathrm{mL})$ were freshly prepared by dilution of the stock standard solutions with mobile phase. Mixture solutions containing analytes were freshly prepared, by mixing appropriate volumes of the corresponding working standard solutions in volumetric flask and made up to the mark with mobile phase.

\section{Commercial syrups}

Syrup equivalent to $4 \mathrm{mg}$ of CPM and $20 \mathrm{mg}$ of LCF was transferred to a $100 \mathrm{ml}$ volumetric flask and volume was made up mark with methanol. An aliquot $(1 \mathrm{ml})$ of the solution was transferred to $10 \mathrm{~m}$ volumetric flask and diluted to the mark with mobile phase. The solutions were filtered through $0.45-\mathrm{mm}$ Millipore filter before injection. All preparations were performed in triplicate for each brand.

\section{Chromatographic conditions}

Chromatographic separation was performed on $\mathrm{C}_{18}(25 \mathrm{~cm} \times$ $0.46 \mathrm{~cm}$ ) Hypersil BDS column. The mobile phase comprised of buffer ( $\mathrm{pH}$ 6.5)-acetonitrile $(50: 50, \% \mathrm{v} / \mathrm{v})$. The mobile phase was delivered at a flow rate of $1 \mathrm{mlmin}^{-1}$. Analysis was performed at ambient temperature. Injection volume was $20 \mu \mathrm{l}$ and detection was carried out at $227 \mathrm{~nm}$.

\section{Results and Discussion \\ Selection of wavelength}

Figure 3, depicts the UV spectra of CPM and LCF, dissolved in the mobile phase. CPM and LCF are in the ratio found in pharmaceutical formulations; both drugs show iso-absorptive absorption at $227 \mathrm{~nm}$, so considered to be the most desirable detection wavelength.

\section{Optimization of mobile phase}

Factors such as solubility and pKa (9.47 for CPM and 8.82 for LCF) of both the drugs were utilised to develop mobile phase. Only $\mathrm{CPM}$ was found to be eluting in initial trials with water: methanol and water: acetonitrile. This tempted to have buffer in mobile phase. With the convention that $\mathrm{pH}$ of mobile phase should (ideally) be at least $2 \mathrm{pH}$ units below or above the sample $\mathrm{pKa} 10 \mathrm{mM}$ phosphate buffer of $\mathrm{pH} 6$ was used [23]. With water (pH 6.0): methanol (40:60 \%v/v) LCF eluted, but both peak for CPM and LCF were poorly resolved with retention time (Rt) 2.73 and $2.87 \mathrm{~min}$ respectively. When strength of organic modifier methanol was decreased to $30 \%$ gradually, capacity factor $(\mathrm{k})$ for both increases i.e. Rt increases to 3.1 and $4.5 \mathrm{~min}$. Selectivity ( $\alpha$ ) was increased by replacing methanol with acetonitrile, results in increased $\mathrm{k}$ value for LCF, Rt changes to $6.257 \mathrm{~min}$ with tailing. On changing $\mathrm{pH}$ of buffer to $\mathrm{pH} 6.5$ tailing decreases. Hence mobile phase Buffer (pH 6.5, 10mM): Acetonitrile (50:50, \%v/v) with a flow rate of $1 \mathrm{ml} / \mathrm{min}$ was finalized as it resulted in good peak shapes and a significant amount of resolution (Figure 4).

\section{Method validation}

The method was validated in agreement with the ICH guideline [24]. So, method linearity in the relevant working ranges, precision, accuracy, specificity, and robustness were evaluated. System suitability was also determined.

\section{Range and linearity}

Method range and linearity were evaluated with seven mixtures of standards at the concentrations: $2.0-6.0 \mu \mathrm{g} / \mathrm{mL}$ for CPM and 10.0- $30.0 \mu \mathrm{g} / \mathrm{mL}$. Samples were injected in triplicate and calibration curves were plotted against the standard drug concentrations versus peak areas of the individual drugs. The calibration curves for both the drugs were characterized by the equations shown in Table 1 ; In addition, correlation coefficients $>0.999$ confirms method linearity.

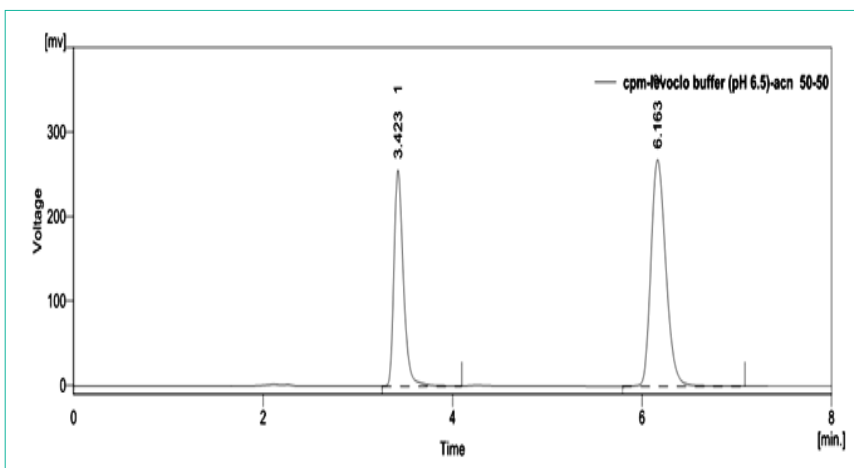

Figure 4: Chromatogram of Standard CPM and LCF in Buffer $(\mathrm{pH} 6.5)$ Acetonitrile $(50: 50, \% \mathrm{v} / \mathrm{v})$ with flow rate $1 \mathrm{ml} / \mathrm{min}$. 
Table 1: Result of Linearity study.

\begin{tabular}{|c|c|c|c|c|}
\hline \multirow{2}{*}{$\%$ of nominal } & CPM & Mean & LCF & Mean \\
\hline & $(\mu \mathrm{g} / \mathrm{mL})$ & AUC $(n=3)$ & $(\mu \mathrm{g} / \mathrm{mL})$ & $\operatorname{AUC}(n=3)$ \\
\hline 50 & 2 & 881.46 & 10 & 1412.37 \\
\hline 75 & 3 & 1320.43 & 15 & 2116.27 \\
\hline 100 & 4 & 1789.49 & 20 & 2868.67 \\
\hline 125 & 5 & 2202.79 & 25 & 3531.59 \\
\hline 150 & 6 & 2673.02 & 30 & 4260.36 \\
\hline Slope & \multicolumn{2}{|c|}{446.55} & \multicolumn{2}{|c|}{142.23} \\
\hline Intercept & \multicolumn{2}{|c|}{-12.75} & \multicolumn{2}{|c|}{-6.67} \\
\hline$r^{2}$ & \multicolumn{2}{|c|}{0.9997} & \multicolumn{2}{|c|}{0.9997} \\
\hline
\end{tabular}

Table 2: Result of Inter-day and Intraday precision.

\begin{tabular}{|c|c|c|c|c|c|}
\hline \multirow{3}{*}{ Drug } & \multirow{3}{*}{$\begin{array}{l}\text { Conc. } \\
(\mu \mathrm{g} / \mathrm{mL})\end{array}$} & \multicolumn{2}{|c|}{ Repeatability $(n=6)$} & \multicolumn{2}{|c|}{ Inter-day $(n=3)$} \\
\hline & & \multirow{2}{*}{$\begin{array}{c}\text { Area } \\
\text { Mean } \pm \text { S.D. }(n=6)\end{array}$} & \multirow{2}{*}{ \% R.S.D } & Area & \multirow{2}{*}{ \% R.S.D } \\
\hline & & & & Mean \pm S.D. $(n=3)$ & \\
\hline \multirow{3}{*}{ CPM } & 2 & & & $888.13 \pm 9.25$ & 1.042 \\
\hline & 4 & $1777.84 \pm 10.69$ & 0.6 & $1778.12 \pm 13.42$ & 0.755 \\
\hline & 6 & & & $2677.29 \pm 29.76$ & 1.111 \\
\hline \multirow{3}{*}{ LCF } & 10 & & & $1425.94 \pm 10.05$ & 0.705 \\
\hline & 20 & $2843.62 \pm 10.18$ & 0.36 & $2845.13 \pm 14.56$ & 0.512 \\
\hline & 30 & & & $4277.60 \pm 50.83$ & 1.305 \\
\hline
\end{tabular}

\section{Precision}

Method precision was verified in its repeatability and intermediate precision. The ICH guideline Q2(R1) [24] offers two alternatives for assessing repeatability. One needs triplicate estimation with independently prepared samples at low, medium and high analyte levels or in other six replicate determinations at 100\% level.

Nine independent mixed standards samples containing both analytes at $80 \%, 100 \%$, and $120 \%$ of their corresponding expected concentrations in the pharmaceutical formulation were injected and the RSD (\%) of their recoveries were determined. The observed RSD levels (Table 2), which were below $2 \%$, were considered satisfactory.

For verifying intermediate precision, the samples were injected at random during three different days. In all cases results were consistent $(\mathrm{RSD}<2 \%)$, confirmed the precision of the method (Table 2).

\section{Accuracy}

Method accuracy was demonstrated by standard addition method, by evaluating declared amounts of standard drugs which was fortified to pre-assayed pharmaceutical formulation sample $(2.0 \mu \mathrm{g} /$
Table 4: Limit of Detection and Quantification.

\begin{tabular}{|c|c|c|}
\hline & LOD $(\mu \mathrm{g} / \mathrm{mL})$ & LOQ $(\mu \mathrm{g} / \mathrm{mL})$ \\
\hline CPM & 0.108 & 0.327 \\
\hline LCF & 0.496 & 1.504 \\
\hline
\end{tabular}

Table 5: Result of Robustness study.

\begin{tabular}{|c|c|c|c|}
\hline Parameter & Modification & CPM & LCF \\
\hline \multirow{2}{*}{ Flow rate } & 0.8 & $3.20 \pm 0.02$ & $3.70 \pm 0.02$ \\
\cline { 2 - 4 } & 1.2 & $5.83 \pm 0.06$ & $6.27 \pm 0.06$ \\
\hline \multirow{2}{*}{$\mathrm{pH}$} & 6.3 & $1786.36 \pm 9.46$ & $1814.25 \pm 7.43$ \\
\cline { 2 - 4 } & 6.7 & $2870.71 \pm 8.40$ & $2909.02 \pm 23.70$ \\
\hline \multirow{2}{*}{ Organic modifier } & 48.0 & $1742.73 \pm 14.28$ & $1830.12 \pm 15.39$ \\
\cline { 2 - 4 } & 52.0 & $2800.49 \pm 13.88$ & $2928.82 \pm 15.94$ \\
\hline
\end{tabular}

$\mathrm{mL}$ CPM and $10.0 \mu \mathrm{g} / \mathrm{mL} \mathrm{LCF})$, at $80 \%, 100 \%$, and $120 \%$ in triplicates. The \%RSD did not exceed $2 \%$ (Table 3 ), meaning that essentially quantitative recoveries were achieved. This confirmed the method enables the accurate determination of the analytes.

\section{LOD and LOQ}

The ICH guidelines do not specifically need calculation of the limits of detection (LOD) and quantification (LOQ) for principal analytes in their formulations. However, to assess the confirmed concentration ranges of the analytes were above their LOQ values, the LOD and LOQ were determined employing the ICH method based on the calibration curve [24]. The LOD values were $0.108 \mu \mathrm{g} /$ $\mathrm{mL}$ for CPM and $0.496 \mu \mathrm{g} / \mathrm{mL}$ for LCF; the corresponding LOQ values, determined with the same method, were 0.327 and $1.504 \mu \mathrm{g} /$ $\mathrm{mL}$, respectively. These values fall below the lowest expected analyte concentrations in the samples (Table 4).

\section{Robustness}

The robustness of the method was assessed by deliberately causing small changes to the procedure. The flow rate $(1 \mathrm{~mL} / \mathrm{min})$ was altered by $\pm 2 \mathrm{ml} / \mathrm{min}(0.8-1.2)$, the $\mathrm{pH}$ of the aqueous phase (6.5) was modified in \pm 0.2 units (6.3-6.7), and the proportion of the organic mobile phase content (50) was changed in $\pm 2 \mathrm{~mL}$ (48-52\%). The results were repeated in triplicate and summarized in Table 5. Results indicates its reliability during normal use.

\section{System suitability}

System suitability parameters must be performed to ensure that the system is working correctly during the analysis. The SST parameters were evaluated by injecting six replicates of a solution containing $4 \mu \mathrm{g} / \mathrm{mL} \mathrm{CPM}$ and $20 \mu \mathrm{g} / \mathrm{mL}$ of LCF. The observed RSD values for different parameters were reported, respectively (Table

Table 3: Result of Recovery study $(n=3)$.

\begin{tabular}{|c|c|c|c|c|c|}
\hline Drug & $\%$ level & Spiked Conc. $(\mu \mathrm{g} / \mathrm{mL})$ & Recovered Conc. $(\mu \mathrm{g} / \mathrm{mL})$ & Mean Recovery (\%) & R.S.D (\%) \\
\hline \multirow{3}{*}{$\begin{array}{c}\text { CPM } \\
(2.0 \mu \mathrm{g} / \mathrm{mL})\end{array}$} & 80 & 1.6 & 1.61 & 100.63 & 0.63 \\
\hline & 100 & 2 & 1.99 & 99.33 & 1.05 \\
\hline & 120 & 2.4 & 2.41 & 100.28 & 1.28 \\
\hline \multirow{3}{*}{$\begin{array}{c}\text { LCF } \\
(10.0 \mu \mathrm{g} / \mathrm{mL})\end{array}$} & 80 & 8 & 8.04 & 100.46 & 0.58 \\
\hline & 100 & 10 & 9.91 & 99.1 & 0.4 \\
\hline & 120 & 12 & 11.97 & 99.73 & 0.93 \\
\hline
\end{tabular}


Table 6: Results for system suitability test $(n=6)$.

\begin{tabular}{|c|c|c|c|}
\hline \multirow{2}{*}{ Parameter } & CPM & LCF & \multirow{2}{*}{ Acceptance Limit } \\
\cline { 2 - 4 } & \multicolumn{2}{|c|}{ Average $(\mathbf{n = 6}) \pm \%$ RSD } & \\
\hline Retention Time $\left(t_{r}\right.$, min.) & $3.319 \pm 0.14$ & $6.118 \pm 0.18$ & $\% R S D<2 \%$ \\
\hline Resolution $\left(R_{s}\right)$ & \multicolumn{2}{|c|}{$11.655 \pm 0.76$} & $R s>2$ \\
\hline Tailing factors $\left(t_{f}\right)$ & $1.21 \pm 0.05$ & $1.32 \pm 0.08$ & $T f \leq 2.0$ \\
\hline Theoretical plates $(N)$ & $5706 \pm 47.44$ & $7282 \pm 123.55$ & $\mathrm{~N} \geq 2000$ \\
\hline
\end{tabular}

Table 7: Results of marketed formulation analysis.

\begin{tabular}{|c|c|c|c|c|}
\hline \multirow{2}{*}{ Analyte Dosage form } & \multicolumn{2}{|c|}{ Label claim (mg) } & \multicolumn{2}{|c|}{ Assay (\% of label claim*) } \\
\cline { 2 - 6 } & CPM & LCF & CPM & Mean \pm S. D. \\
\cline { 2 - 5 } & LCF \\
\hline Levotus Syrup & 4 & 20 & $99.84 \pm 0.421$ & $99.57 \pm 0.416$ \\
\hline
\end{tabular}

$6)$, in full compliance with the commonly accepted values $(<2 \%)$. Method performance data including column efficiencies $(\mathrm{N})$ capacity factors $(k)$, selectivity $(\alpha)$, resolutions between adjacent peeks $(R s)$, and tailing factors $\left(t_{f}\right)$ are also listed. All parameters were within acceptable limits.

\section{Analysis of marketed formulation by developed method}

The validated HPLC method was applied to the simultaneous determination of the analytes in syrup formulation (Levotus). Analyses were carried out in triplicate and the results (mean and RSD) are shown in Table 7.

The data showed recoveries between $99.84 \%$ and $99.57 \%$ of label claim of the different analytes, with satisfactory precision (RSD $\leq 2 \%$, $\mathrm{n})$. These results confirmed the amount of each active principal in the samples was close to the declared content.

No extra peaks which could interfere with the determination of the analytes were observed and the determinations of both drugs were accurately achieved with good recovery and precision. Therefore, the proposed method can be confidently employed for the quality control syrups containing the pharmaceutical combination of CPM and LCF (Table 7).

The test results were comparable to labelled value of each drug in syrup. These results show the developed method is accurate, precise, simple and rapid. It can be used in the routine quality control of dosage form in industries.

\section{Conclusion}

A reliable and rapid liquid chromatography method for the simultaneous estimation of CPM and LCF in syrup preparations has been developed and validated. The method is capable of separating the active principles within $10 \mathrm{~min}$. In addition, the results suggest the method is sensitive, linear, precise, accurate, specific, and robust for the mixture under investigation. So, the method can be safely applied to the quality control of CPM and LCF in its formulation.

\section{Acknowledgement}

The authors wish to express their heartfelt regards to Shri D. D. Patel President, Om Gayatri Education \& Charitable Trust and Pioneer Pharmacy Degree College for his valuable guidance and support. Authors are grateful to LGM Pharma, for providing the drug sample and the Management of Pioneer Pharmacy Degree College for providing necessary research facilities.

\section{References}

1. Drug profile for Chlorpheniramine maleate. 2015

2. DM Paton, DR Webster. Clinical pharmacokinetics of $\mathrm{H} 1$ - receptor antagonists (the antihistamines). Clin. Pharmacokinet. 1985; 10: 477-497.

3. Drug profile for levocloperastine fendizoate.

4. MA Catania, S Cuzzocrea. Pharmacological and clinical overview of cloperastine in treatment of cough. Ther. Clin. Risk Manage. 2011; 7: 83-92.

5. Nalini K, Narmada P, G Vijaya lakshmi, Gowtham Y, Jogi KV. Simultaneous estimation of paracetamol, guaiphensin, phenylepherine, chlorpheniramine maleate, and Bromhexine $\mathrm{HCl}$ in combined tablet dosage form by RP-HPLC. Int. J. of Pharma. Sci. and Res. 2014; 5: 410-416.

6. Rajurkar S. Simultaneous determination of chlorpheniramine maleate, paracetamol and Pseudoephedrine $\mathrm{HCl}$, in pharmaceutical preparation by HPLC. Int. J. Life Sci Pharm Research. 2011; 1: 94-100.

7. Abdulbari MM, Ihsan MSH. Simultaneous determination and validation of chlorpheniramine maleate, acetaminophen, phenylpropanolamine hydrochloride and caffeine in tablet dosage form by using reverse phase high performance liquid chromatography (RP-HPLC). Int. J. Pharm Pharm. Sci. 2013; 5: 666-670.

8. Shah DA, Doshi SS, Baldania SL, Chhalotiya UK, Bhatt KK. Development of LC Method for Estimation of diethyl carbamazine citrate and chlorpheniramine maleate in combined dosage form. Turk J. Pharm. Sci. 2014; 11: 79-86.

9. Khalode KD, Waiker SB, Padmane SP. A Validated RP-HPLC Method for the simultaneous estimation of dextromethorphan hydrobromide and chlorpheniramine maleate in syrup formulation. Am. J. Pharm Tech Res. 2012; 2: 392-394.

10. Sanchaniya PM, Mehta FA, Uchadadiya NB. Development and Validation of an RP-HPLC Method for Estimation of Chlorpheniramine Maleate, Ibuprofen, and Phenylephrine Hydrochloride in Combined Pharmaceutical Dosage Form, Chromatography Research International. 2013; 6.

11. Daravath B, Reddy GS, Kamarupu SK. A Validated RP-HPLC Method for the simultaneous estimation of Diethylcarbamazine citrate and chlorpheniramine maleate in combined pharmaceutical dosage form". Asian J. of Pharma and Clinical Research. 2014; 7: 98-102.

12. Vignaduzzo SE, Kaufman TS. Development and Validation of A HPLC Method for the Simultaneous Determination of Bromhexine, Chlorpheniramine, Paracetamol, and Pseudoephedrine in Their Combined Cold Medicine Formulations. J Liq Chromatography and Related Tech. 2013; 36: 2829-2843.

13. Vijay Anand PR, Deepika N, Sam Solomon WD, Venkatanarayan R. RPHPLC Method development and Validation for Simultaneous determination of Codeine phosphate, Chlorpheniramine maleate and Sodium benzoate in cough syrup formulation. J Pharm Research. 2012; 5: 949-953.

14. Qi ML, Wang P, Leng YX, Gu JL, Fu RN. Simple HPLC method for simultaneous determination of acetaminophen, caffeine and chlorpheniramine maleate in tablet formulations. Chromatographia. 2002; 56: 295-298.

15. Wanjari DB, Parashar VV, Lulay SN, Tajne MR, and Gaikwad NJ. Simultaneous HPLC Estimation of Acetaminophen, Chlopheniramine Maleate, Dextromethorphan Hydrobromide and Pseudoephedrine Hydrochloride in Tablets. Indian J Pharm Sci. 2004; 66: 345-347.

16. Sarve S, Lokhande R, Sutar R, Pandekar S. Simultaneous estimation of Guaiphensin, Ambroxol $\mathrm{HCl}$, pseudoephedrine and chlorpheniramine in combined dosage form by RP-HPLC. J Chem Pharm Res. 2014; 6: 15771582.

17. Al-Shaalan NH. Determination of phenylephrine hydrochloride and chlorpheniramine maleate in binary mixture using chemometric-assisted spectrophotometric and high-performance liquid chromatographic-UV methods. J Saudi Chem Soc. 2010; 14: 15-21.

18. Hassan EM, Mahrous MS, Shdeed RN. Spectrophotometric determination 
of the active components of a ternary mixture containing Chlorpheniramine maleate, Diclofenac sodium and Paracetamol. J Pharm Biomed Sci. 2011 7: $1-9$.

19. Wadher SJ, Kalyankar TM, Panchal PP. Development and validation of simultaneous estimation of chlorpheniramine maleate and phenylepherine $\mathrm{HCl}$ in bulk and capsile dosage form by UV spectrophotometer. Int J Chem Tech Research. 2013; 5: 2410-2419.

20. Al-Kayasi HN, Salem MS. Simultaneous Quantitative Determination of Codeine Phosphate, Chlorpheniramine Maleate, Phenylephrine Hydrochloride and Acetaminophen in Pharmaceutical Dosage Forms Using Thin Layer Chromatography Densitometry. Analytical Letter. 1986; 19: 915924

21. Gercia A, Ruperej FJ, Ceppa F, Pellati F, Barbas C. Development of Chromatographic method for the determination of genotoxic impurities in cloperastine fendizoate. J Pharm Biomed Anal. 2012; 61: 230-233.
22. Jain NA, Umekar MJ, Lohiya RT. Spectrophotometric method development for determination of levocloperastine fendizoate in bulk and pharmaceutical dosage form. Asian J Research Chem. 2011; 4: 1231-1234.

23. LR Synder, JJ Kirkland, JL Glajch (Eds.). Practical HPLC Method Development, Wiley, New York, 1997, p. 295.

24. ICH Guide Q2(R1). Validation of Analytical Procedures- Text and Methodology. International Conference on Harmonization of Technical Requirements for Registration of Pharmaceuticals for Human Use $(\mathrm{ICH})$, Geneva, Switzerland, 2005.
Austin J Anal Pharm Chem - Volume 4 Issue 2 - 2017

ISSN : 2381-8913 | www.austinpublishing group.com

Meshram et al. () All rights are reserved
Citation: Sharma B, Satone D, Pradhan P, Jain $\mathrm{H}$ and Meshram D. Development and Validation of RP-HPLC Method for Simultaneous Estimation of Levocloperastine Fendizoate and Chlorpheniramine Maleate in their Combined Dosage Form. Austin J Anal Pharm Chem. 2017; 4(2): 1083 